Tropical Journal of Pharmaceutical Research February 2020; 19 (2): 383-389

ISSN: $1596-5996$ (print); 1596-9827 (electronic)

(c) Pharmacotherapy Group, Faculty of Pharmacy, University of Benin, Benin City, 300001 Nigeria.

\title{
Knowledge, attitude and perception on PharmD program among penultimate and final-year undergraduate pharmacy students in a Nigerian university - An intervention study
}

\author{
Akinniyi A Aje ${ }^{1 *}$, Augustine O Okhamafe ${ }^{2}$ \\ ${ }^{1}$ Department of Clinical Pharmacy and Pharmacy Administration, Faculty of Pharmacy, University of Ibadan, Ibadan, \\ ${ }^{2}$ Department of Pharmaceutics \& Pharmaceutical Technology, Faculty of Pharmacy, University of Benin, Benin City 300001, \\ Nigeria
}

${ }^{*}$ For correspondence: Email: aje123@gmail.com; Tel: +234-8035684484

Sent for review: 7 November 2019

Revised accepted: 4 February 2020

\begin{abstract}
Purpose: To carry out an interventional study on the knowledge, attitude and perception of penultimate and final year undergraduate pharmacy students of the University of Ibadan on Doctor of Pharmacy (PharmD) program.

Methods: A cross-sectional study was carried out among penultimate and final-year undergraduate students of the Faculty of Pharmacy, University of Ibadan using semi-structured questionnaire. A seminar was organized for the intervention group. The data were summarized using descriptive and inferential statistics.

Results: Pre-intervention PharmD knowledge assessment of majority, 63 (94.0\%) control group and 63 $(87.5 \%)$ intervention group participants was below average. Post-intervention, $38(52.8 \%)$ intervention group participants had satisfactory scores, while 54 (80.6\%) of control group had below average scores. Generally, the participants had good PharmD attitude and perception. There was a significant difference $(p<0.001)$ between pre- and post-intervention PharmD knowledge assessment among the intervention group. A significant difference $(p<0.001)$ was observed between the post-intervention PharmD knowledge of the control group and the intervention group.

Conclusion: Baseline below average PharmD knowledge of study participants improved significantly in the intervention group post-intervention. Generally, the participants had a good attitude and perception towards the PharmD program.
\end{abstract}

Keywords: PharmD, Pre-post intervention, Undergraduate pharmacy students, Knowledge, Attitude, Perception, University of Ibadan

This is an Open Access article that uses a fund-ing model which does not charge readers or their institutions for access and distributed under the terms of the Creative Commons Attribution License (http://creativecommons.org/licenses/by/4.0) and the Budapest Open Access Initiative (http://www.budapestopenaccessinitiative.org/read), which permit unrestricted use, distribution, and reproduction in any medium, provided the original work is properly credited.

Tropical Journal of Pharmaceutical Research is indexed by Science Citation Index (SciSearch), Scopus, International Pharmaceutical Abstract, Chemical Abstracts, Embase, Index Copernicus, EBSCO, African Index Medicus, JournalSeek, Journal Citation Reports/Science Edition, Directory of Open Access Journals (DOAJ), African Journal Online, Bioline International, Open-J-Gate and Pharmacy Abstracts

\section{INTRODUCTION}

It is no longer news that the PharmD program has been approved in Nigeria in 2016 and any
Pharmacy School adequately equipped for the program may commence the training sequel to Nigeria University Commission approval. However, it is important to find out the 
knowledge, attitude and perceptions of some undergraduate students in a Nigerian Faculty of Pharmacy about the program. This becomes critical as the focus is no longer theoretical didactic lectures but practical and experiential based approach. Students' knowledge, attitude and perception of the PharmD program will surely be a useful tool in the program development.

National projected growth for the pharmacy profession in the US is anticipated at $14 \%$ between 2012 and 2022, according to the US Bureau of Labor Statistics [1]. Factors contributing to the proposed projected growth include the aging population, availability of new drug products, and increasing complexity of the health care system. The Bureau of Labor Statistics' projections are corroborated by the US Department of Health and Human Services, which anticipates that national need for pharmacists will increase $1.4 \%$ annually through 2030 [2].

Based on this information, pharmacy seems to be a good career choice [3]. However, it is important for every school of pharmacy to update the quality of their training, such that their products will be able to effectively practice anywhere on the world stage. Although a couple of pharmacy schools are already accredited by the Nigerian University Commission to offer the PharmD program, it is important to set machineries in place by way of research to assist with informed decision making as regards the implementation of PharmD program in Pharmacy schools.

A doctor of pharmacy degree program must have a multidisciplinary curriculum that produces pharmacists with sufficient mental acuity to differentiate their position from that of simply dispensers of drugs to that of providers of pharmaceutical care [4]. The PharmD program in the United States is the epitome of the practicebased model as it evolved from industrial and compounding pharmacy to a more patientfocused program [4]. Now, as there is an upsurge in clinical pharmacy component of the training, many developing countries have expanded their pharmacy curriculum to a 5- or 6year program that culminates in a Doctor of Pharmacy (PharmD) degree [4].

According to the International Pharmaceutical Federation, there must be well-planned execution of good pharmacy practice in developing countries. Thus, the implementation of the Pharm D program must largely emphasize pharmaceutical care encompassing areas of patient care such as hospital and clinical pharmacy. It should not be used as a tool for the pharmacist to be employed internationally or as a sole instrument of professional power and status [4]. Research on the focus of the study is scanty in Nigeria and this study therefore aims to provide objective data as regards the PharmD program.

\section{Rationale for the study}

PharmD curriculum was recently approved by the Nigerian University Commission for Pharmacy schools that have the prerequisite requirements to run the program. To the best of the researcher's knowledge, no research has been published on this all-important issue in Nigeria. However, the need for research on the PharmD program, especially concerning the pharmacy students, who are the recipients, becomes necessary for effective implementation of the program. The study aims to determine the knowledge attitude and perception (KAP) of penultimate and final year undergraduate pharmacy student about the pharmD program. The study also seeks to identify gaps and the impact of an educational intervention on the KAP of a group of the respondent.

\section{METHODS}

\section{Study population}

This consisted of penultimate and final year undergraduate students of the Faculty of Pharmacy, University of Ibadan, Ibadan, Nigeria.

\section{Study design}

The study was a pre-post interventional, crosssectional study.

\section{Sample size}

All penultimate and final year undergraduate student who gave consent were sampled.

\section{Inclusion/exclusion criteria}

Penultimate and final year students of the Faculty of Pharmacy, University of Ibadan who gave their consents were recruited for the study while those who declined consent were excluded.

\section{Selection of controls}

The penultimate year students of the Faculty of Pharmacy, University of Ibadan served as the 
control group while the final year students were the intervention group.

\section{Study instrument}

A semi-structured questionnaire was used as the data collection instrument for the study. The instrument was prepared by the investigator after a thorough literature search. The research tool was subjected to face validity by pretesting among selected students. The content of the questionnaire was validated by a lecturer in the University of Ibadan and another lecturer in the Faculty of Pharmacy, University of Benin, both in Nigeria. The 24-item structured questionnaire was divided into three sections: Section A was for socio-demographic characteristics of the participants, Section B addressed the PharmD knowledge assessment and Section C addressed both attitude and perception. The PharmD knowledge assessment section had dichotomous questions with either 'yes' or 'no' as options and some questions requiring participants to list correct responses. The PharmD attitude and perception section had graded response options from a Likert scale.

\section{Data collection procedure}

The pretested semi-structured questionnaire was administered study participants (penultimate and final year students) who gave their consent after explaining the purpose of the study to them. They were asked to complete the questionnaire which was collected immediately after. The same questionnaire was administered a month after Educational intervention was in order to measure the impact of the intervention.

\section{Intervention package}

The intervention was in form of a seminar carried out among the intervention group. Emphasis was placed on the gaps discovered, aside from general information on the PharmD program.

\section{Ethical issues}

Ethical approval (no. UI/EC/19/0163) was granted the study by University of Ibadan/University College Hospital Ethics Committee. Participants' consent were sought after explaining the purpose of the study to them and only those who gave consent were recruited for the study. The study was carried out by following the principles outlined in Helsinki Declaration of 1964, as amended [5].

\section{Statistical analysis}

Data was summarized with descriptive statistics such as frequency counts, percentages, means, and standard deviation. Inferential statistics such as independent-sample t-test determine the difference between the mean PharmD knowledge assessment scores for the 400 and 500 level participants), paired-samples t-test (to determine of the difference between the pre- and post-intervention mean PharmD knowledge assessment scores for each level), MannWhitney $U$ test (to determine the difference between the mean rank PharmD attitude and perception assessment scores for the 400 and 500 level participants) and Wilcoxon signed rank test was done to determine significance of the difference between the pre- and post-intervention mean rank PharmD attitude and perception assessment scores for each level. Level of significance was set as $p<0.05$. Each correct response was given a mark while incorrect responses were awarded zero mark and negatively worded questions on the Likert scale were reversed. The marks were summed and converted to percentages for ease of categorization. The categories are in Table 1.

\section{RESULTS}

The questionnaire response rate was $71.4 \%: 132$ participants completed the study out of a population of 185 participants. The gender distribution for both the intervention and control group was fairly even. The mode of entry to Faculty of Pharmacy of majority of the participants, 62 (92.5\%) for 400 level and 60 (83.3\%) for 500 level, was through the Unified Tertiary Matriculation Examinations. Six $(9.0 \%)$ and $8(11.1 \%)$ participants from 400 and 500 level, respectively had previous degree before admission to the Faculty of Pharmacy. A detailed account of the participants' socio-demographic characteristics is presented in Table 2.

Table 1: Categorization of PharmD assessment scores

\begin{tabular}{lccc}
\hline Category & Knowledge assessment & Attitude assessment & Perception assessment \\
\hline Below average $(<50.0 \%)$ & $<12$ & $<18$ & $<15$ \\
Satisfactory $(50.0-69.9 \%)$ & $12-16$ & $18-24$ & $15-21$ \\
Good $(70.0-89.9 \%)$ & $17-20$ & $25-31$ & $22-26$ \\
Excellent $(90.0-100.0 \%)$ & $21-23$ & $32-35$ & $27-30$ \\
Total obtainable mark & 23 & 35 & 30 \\
\hline
\end{tabular}


The PharmD knowledge of the intervention group improved after the intervention, with participants showing better scores (Table 3). Not much difference was observed with the pre- and postintervention PharmD attitude and perception of both the intervention and the control group (Table 4). The PharmD knowledge assessment category of majority of the participants, 63 (94.0 $\%)$ control group and $63(87.5 \%)$ intervention group, fell within the 'below average' category (Table 5). Post-intervention, 38 (52.8\%) of the intervention group participants had 'satisfactory' category scores and $15(20.8 \%)$ had 'good' category scores. The control group had 54 (80.6 $\%$ participants in the 'below average' category. Generally, the participants had good PharmD attitude and perception. Minimal changes were observed with the pre- and post-intervention PharmD attitude and perception amongst both the control and intervention group (Table 5).

Paired-samples t-test revealed a significant difference $(p<0.001)$ between the preintervention (8.97 \pm 2.40$)$ and the postintervention PharmD knowledge assessment (13.24 $\pm 3.05 ; t=13.89)$ among the intervention group (500 level). The independent-samples ttest showed a significant difference $(p<0.001)$ between the post-intervention PharmaD knowledge of the control group i.e. 400 level $(9.37 \pm 2.46)$ and the intervention group i.e. 500 level $(13.24 \pm 3.05 ; t=8.19)$.

Table 2: Socio-demographic characteristics of participants

\begin{tabular}{llcc}
\hline & & \multicolumn{2}{c}{ Frequency (\%) } \\
\cline { 3 - 4 } Variable & Description of variable & $\mathbf{4 0 0}$ Level & $\mathbf{5 0 0 ~ L e v e l ~}$ \\
Gender & Female & $\mathbf{( N = 6 7 )}$ & $40(55.6)$ \\
Mode of entry & $30(44.8)$ & $32(44.4)$ \\
& Male & $37(55.2)$ & $12(16.7)$ \\
Religion & Direct entry & $5(7.5)$ & $60(83.3)$ \\
& Unified Tertiary Matriculation Exam. & $62(92.5)$ & $61(84.7)$ \\
Previous degree & $53(79.1)$ & $121(15.3)$ \\
& Christianity & $14(20.9)$ & $64(88.9)$ \\
Hall of residence & Islam & $61(91.0)$ & $8(11.1)$ \\
& Yes & $6(9.0)$ & $6(8.3)$ \\
& Awolowo & $5(7.5)$ & $2(2.8)$ \\
& Bello & $4(6.0)$ & $5(6.9)$ \\
& Independence & $9(13.4)$ & $4(5.6)$ \\
& Kuti & $4(6.0)$ & $7(9.7)$ \\
& Mellanby & $2(3.0)$ & $8(11.1)$ \\
& Nnamdi Azikiwe & $7(10.4)$ & $8(11.1)$ \\
& Off-campus & $9(13.4)$ & $8(11.1)$ \\
& Queen Elizabeth & $10(14.9)$ & $17(23.6)$ \\
& Queen Idia & $10(14.9)$ & $2(2.8)$ \\
& St. Annes & $1(1.5)$ & $5(6.9$ \\
\hline
\end{tabular}

Table 3: Pre- and post-intervention PharmD knowledge assessment of participants $\left(\mathrm{N}_{400 \mathrm{~L}}=67, \mathrm{~N}_{500 \mathrm{~L}}=72\right)$

\begin{tabular}{|c|c|c|c|c|}
\hline \multirow[b]{3}{*}{ Question } & \multicolumn{4}{|c|}{ Frequency (\%) or Mean \pm SD } \\
\hline & \multicolumn{2}{|c|}{ Pre-intervention } & \multicolumn{2}{|c|}{ Post-intervention } \\
\hline & $400 L$ & $500 L$ & $400 L$ & $500 L$ \\
\hline PharmD is equivalent to Master's degree & $14(20.9)$ & $9(12.5)$ & $43(64.2)$ & $63(87.5)$ \\
\hline List five major differences between PharmD and B. Pharm & $1.36 \pm 0.75$ & $1.68 \pm 0.80$ & $1.94 \pm 0.83$ & $2.53 \pm 0.89$ \\
\hline The entry requirement for BPharm and PharmD are the same & $53(79.1)$ & $53(73.6)$ & $56(83.6)$ & $61(84.7)$ \\
\hline List the NUC-accredited pharmacy schools for PharmD in Nigeria that you know & $0.25 \pm 0.50$ & $0.25 \pm 0.44$ & $0.42 \pm 0.74$ & $1.54 \pm 1.15$ \\
\hline List 5 countries where PharmD curriculum is currently operational & $1.87 \pm 1.47$ & $2.21 \pm 1.40$ & $2.22 \pm 1.65$ & $3.29 \pm 1.51$ \\
\hline PharmD is a major criterion to practice in UK hospitals. & $9(13.4)$ & $19(26.4)$ & $7(10.4)$ & $27(37.5)$ \\
\hline The same lecturers who currently run the B Pharm program are suitable to run the & & & & \\
\hline PharmD program. & $24(35.8)$ & $36(50.0)$ & $28(41.8)$ & $51(70.8)$ \\
\hline What is the duration of PharmD program in Nigeria (in years)? & 66 (98.5) & $64(88.9)$ & $63(94.0)$ & 65 (90.3) \\
\hline The current global trend of pharmacy practice is product-focused & $38(56.7)$ & $56(77.8)$ & $37(55.2)$ & $57(79.2)$ \\
\hline The current global trend of pharmacy practice is patient-focused & $50(74.6)$ & $62(86.1)$ & $58(86.6)$ & $66(91.7)$ \\
\hline $\begin{array}{l}\text { List the Departments in the Faculty of Pharmacy that will become irrelevant once } \\
\text { the PharmaD curriculum is approved in the University of Ibadan }\end{array}$ & $27(40.3)$ & $36(50.0)$ & $29(43.3)$ & $46(63.9)$ \\
\hline Mean score for PharmD knowledge assessment & $7.67 \pm 2.38$ & $8.97 \pm 2.40$ & $9.37 \pm 2.46$ & $13.24 \pm 3.05$ \\
\hline
\end{tabular}


Table 4: Pre- and post-intervention assessment of participants' PharmD attitude and perception

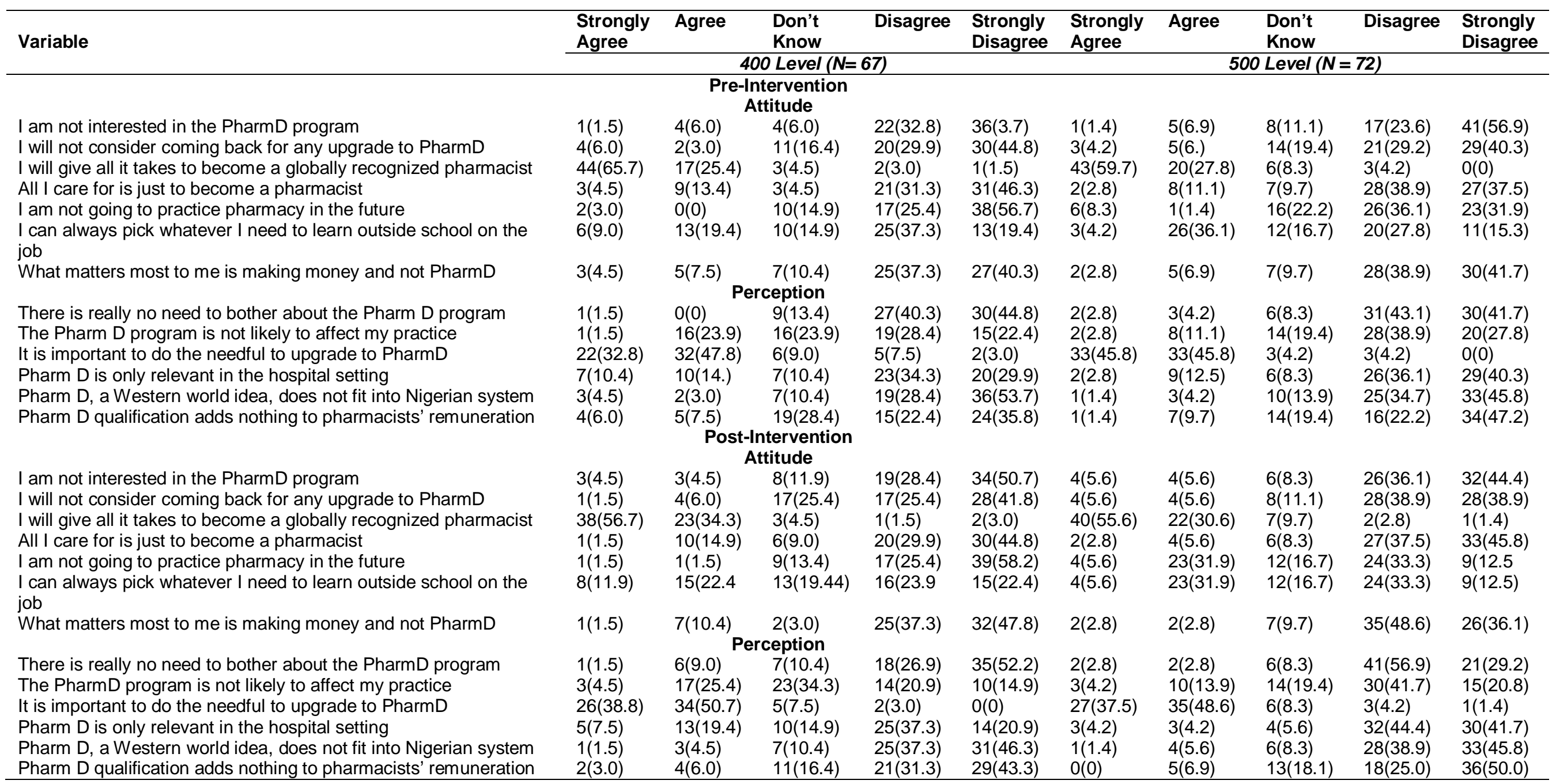


Table 5: Pre- and post-intervention PharmD assessment category of participants $\left(N_{400 L}=67, N_{500 L}=72\right)$

\begin{tabular}{lcccc}
\hline & \multicolumn{4}{c}{ Frequency (Percent) } \\
\cline { 2 - 5 } Variable & \multicolumn{2}{c}{ Pre-Intervention } & \multicolumn{2}{c}{ Post-Intervention } \\
\cline { 2 - 5 } & $\mathbf{4 0 0 L}$ & $\mathbf{5 0 0 L}$ & $\mathbf{4 0 0 L}$ & $\mathbf{5 0 0 L}$ \\
\hline PharmD knowledge assessment & & & & \\
Below average (0-49.9\%) & $63(94.0)$ & $63(87.5)$ & $54(80.6)$ & $19(26.4)$ \\
Satisfactory (50.0-69.9\%) & $4(6.4)$ & $9(12.5)$ & $13(19.4)$ & $38(52.8)$ \\
Good (70.0-89.9\%) & $0(0)$ & $0(0)$ & $0(0)$ & $15(20.8)$ \\
Excellent (90.0-100\%) & $0(0)$ & $0(0)$ & $0(0)$ & $0(0)$ \\
PharmD attitude assessment & & & & \\
Below average (0-49.9\%) & $1(1.5)$ & $1(1.4)$ & $1(1.5)$ & $2(2.8)$ \\
Satisfactory (50.0-69.9\%) & $9(13.4)$ & $17(23.6)$ & $12(17.9)$ & $10(13.9)$ \\
Good (70.0-89.9\%) & $38(56.7)$ & $37(51.4)$ & $38(56.7)$ & $43(59.7)$ \\
Excellent (90.0-100\%) & $19(28.4)$ & $17(23.6)$ & $16(23.9)$ & $17(23.6)$ \\
PharmD perception assessment & & & & \\
Below average (0-49.9\%) & $2(3.0)$ & $2(2.8)$ & $0(0)$ & $1(1.4)$ \\
Satisfactory (50.0-69.9\%) & $19(28.9)$ & $12(16.7)$ & $21(31.3)$ & $12(16.7)$ \\
Good (70.0-89.9\%) & $33(49.3)$ & $32(44.4)$ & $34(50.7)$ & $37(51.4)$ \\
Excellent (90.0-100\%) & $13(19.4)$ & $26(36.1)$ & $12(17.9)$ & $22(30.6)$ \\
\hline
\end{tabular}

Man-Whitney $U$ test showed no significant difference $(p=0.90)$ between the postintervention mean attitude rank for 400 level (70.48) and for 500 level participants (96.56); and also showed no significant difference $(0.12)$ between the post-intervention mean perception rank for 400 level (64.09) and for 500 level participants (74.61). Wilcoxon signed rank test revealed no significant difference between the pre- and post-intervention mean attitude rank for 400 level $(p=0.29)$ and 500 level participants ( $p$ $=0.35)$. There was also an insignificant difference between the pre- and post-intervention mean perception rank between 400 level $(p=$ $0.90)$ and 500 level participants $(p=0.66)$ from the Wilcoxon signed rank analysis.

\section{DISCUSSION}

The baseline PharmD program knowledge among the penultimate and final year students of the Faculty of Pharmacy, University of Ibadan was below average. However, their attitude to and perception of the program was good. The PharmD program knowledge amongst the intervention group improved significantly after the intervention.

The 'below average' PharmD knowledge assessment score category of participants at baseline is as expected. The PharmD curriculum is yet to commence at the University of Ibadan and the students may not have had any opportunity to be exposed to information on PharmD. Also, none of the nearby schools of pharmacy in the Southwestern region of Nigeria currently runs the PharmD curriculum, and as such, there is no possibility of learning from their colleagues in the region since they all run the traditional Bachelor of Pharmacy degree.

However, after the seminar which addressed the knowledge gaps discovered, majority of the intervention group had 'satisfactory' score, which was significantly different from that of the control group. By creating awareness and organizing seminars on the PharmD program, students get to be educated and become better informed on the program. A moderate improvement was also noticed in the PharmD knowledge in the control group. This may be on account of self-study by some of the participants on the subject matter. The questionnaire must have created an awareness and they might have followed up by reading up on the grey areas.

About one-tenth of the participants in both the intervention and control group had a prior degree before being admitted to study pharmacy. The study done by Siracuse and colleagues in US had $19.2 \%$ of respondents earning a prior degree before entering pharmacy school [6]. Aside from the West African Examinations Council, National Examinations Council and the Unified Tertiary Matriculation Examination, no further requirements is compulsory for Nigerian students seeking admission to pharmacy schools. The number of participants with the prior degree before being admitted to study pharmacy shows the level of passion they have for the profession. The PharmD attitude and perception of majority of the participants, both in the control and the intervention groups, was good before and after intervention. Even though they did not know enough on PharmD, they were already open to the PharmD program. This shows that it will be easy to introduce the PharmD program at the University of Ibadan, as the students are 
receptive of the program. This was similar to what was observed in a study carried out in Ethiopia which showed that pharmacy students' attitude to the profession was good [7]. The study carried out among undergraduate pharmacy students at the University of Nigeria also showed that pharmacy students had a good attitude towards pharmaceutical care, which is a focal point for the PharmD program [8]. Another study carried out among pharmacy interns in France also pointed out their positive attitude to pharmaceutical care practice, which culminated from their undergraduate training and brief work exposures [9].

\section{Study limitations}

The results of the study cannot be generalized for the entire country since it was only carried out at a University in Nigeria. Also, the possibility of response bias cannot be ruled out in this study.

\section{CONCLUSION}

The pre-intervention below average PharmD knowledge of study participants improved significantly in the intervention group postintervention. Generally, the participants had a good attitude and perception towards the PharmD program.

\section{DECLARATIONS}

\section{Conflict of interest}

No conflict of interest is associated with this work.

\section{Contribution of authors}

We declare that this work was done by the authors named in this article and all liabilities pertaining to claims relating to the content of this article will be borne by the authors.

\section{Open Access}

This is an Open Access article that uses a funding model which does not charge readers or their institutions for access and distributed under the terms of the Creative Commons Attribution License (http://creativecommons.org/licenses/by/ 4.0) and the Budapest Open Access Initiative (http://www.budapestopenaccessinitiative.org/rea d), which permit unrestricted use, distribution, and reproduction in any medium, provided the original work is properly credited.

\section{REFERENCES}

1. US Bureau of Health Professions. The adequacy of pharmacist supply: 2004 to 2030. US Department of Health and Human Services. Health Resources and Services Administration. 2008. http://bhpr.hrsa.gov/heal thworkforce/reports/pharmsupply20042030.pdf.

Accessed September 2, 2014.

2. US Bureau of Labor Statistics. Occupational outlook handbook. Pharmacists. http://www.bls.gov/ooh/Health care/Pharmacists.htm\#tab-1. Accessed September 2, 2014.

3. Chisholm-Burns MA, Gatwood J, Spivey CA. Economic Analysis of Obtaining a PharmD Degree and Career as a Pharmacist. A J Pharm Edu 2015; 79(8) Article 117. https://doi.org/10.5688/ajpe798117

4. Jamshed S, Babar ZU, Masood I. The PharmD degree in developing countries. Am J Pharm Educ 2007; 71(6): Article 125

5. Bošnjak S. "The declaration of Helsinki: The cornerstone of research ethics". Arch Oncol 2001; 9 (3): 179-184.

6. Siracuse MV, Schondelmeyer SW, Hadsall RS, Schommer JC. Third-Year Pharmacy Students' Work Experience and Attitudes and Perceptions of the Pharmacy Profession. Am J Pharm Edu 2008; 72(3): 50.

7. Beedemariam $G$, Ebro $M$, Ageze $H$, Weldegerima $B$, Legesse B, Tilahun G. Pharmacy Students' Attitude and Future Career Choices: A survey of Four Public Schools of Pharmacy in Ethiopia. E Pharm J 2014; 30(1): 57-63.

8. Udeogaranya PO, Ukwe CV, Obinna I. Ekwunife OI. Assessment of attitudes of University of Nigeria pharmacy students toward pharmaceutical care. Pharm Pract 2009; 7(3): 145-149.

9. Perraudin C, Brion F, Bourdon O, Pelletier-Fleury N. The future of pharmaceutical care in France: a survey of final-year pharmacy students' opinions. BMC Clin Pharmacol. 2011;11(6):1-8. 